\title{
Simulation of the climate impact of Mt. Pinatubo eruption using ECHAM5 - Part 2: Sensitivity to the phase of the QBO and ENSO
}

\author{
M. A. Thomas ${ }^{1}$, M. A. Giorgetta ${ }^{1}$, C. Timmreck ${ }^{1}$, H.-F. Graf ${ }^{2}$, and G. Stenchikov ${ }^{3}$ \\ ${ }^{1}$ Max-Planck Institute for Meteorology, Hamburg, Germany \\ ${ }^{2}$ Center for Atmospheric Sciences, Cambridge University, Cambridge, UK \\ ${ }^{3}$ Department of Environmental Sciences, Rutgers - The State University of NJ, New Jersey, USA
}

Received: 12 March 2008 - Published in Atmos. Chem. Phys. Discuss.: 22 May 2008

Revised: 17 March 2009 - Accepted: 4 May 2009 - Published: 11 May 2009

\begin{abstract}
The sensitivity of the climate impact of Mt. Pinatubo eruption in the tropics and extratropics to different QBO phases is investigated. Mt. Pinatubo erupted in June 1991 during the easterly phase of the QBO at $30 \mathrm{hPa}$ and the phase change to westerly took place in August 1992. Here, the consequences are analyzed if the QBO phase had been in the opposite phase during the eruption of Mt. Pinatubo. Hence, in this study, simulations are carried out using the middle atmosphere configuration of ECHAM5 general circulation model for two cases - one with the observed QBO phase and the other with the opposite QBO phase. The response of temperature and geopotential height in the lower stratosphere is evaluated for the following cases - (1) when only the effects of the QBO are included and (2) when the effects of aerosols, QBO and SSTs (combined response) are included. The tropical QBO signature in the lower stratospheric temperature is well captured in the pure QBO responses and in the combined (aerosol + ocean + QBO) responses. The response of the extratropical atmosphere to the QBO during the second winter after the eruption is captured realistically in the case of the combined forcing showing a strengthening of the polar vortex when the QBO is in its westerly phase and a warm, weak polar vortex in the easterly QBO phase. The vortex is disturbed during the first winter irrespective of the QBO phases in the combined responses and this may be due to the strong influences of El Niño during the first winters after eruption. However, the pure QBO experiments do not realistically reproduce a strengthening of the polar vortex in the westerly QBO phase, even though below normal temperatures in the high latitudes are seen in OctoberNovember-December months when the opposite QBO phase is prescribed instead of the December-January-February winter months used here for averaging.
\end{abstract}

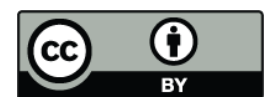

Correspondence to: $\mathrm{M}$. A. Thomas (manu.thomas@zmaw.de)

\section{Introduction}

The quasi-biennial oscillation (QBO) in the zonal winds in the equatorial lower stratosphere is a well known mode of interannual variability. The zonally symmetric easterly and westerly wind regimes alternate regularly with a mean period of 28-29 months. The alternating wind regimes develop in the upper stratosphere near $3 \mathrm{hPa}$ and propagate downward at an approximate rate of $1 \mathrm{~km} /$ month to the tropopause. The amplitude of the easterly phase is stronger than the westerly phase. The easterly zonal winds can reach as high as 35$40 \mathrm{~m} / \mathrm{s}$, whereas the westerly zonal winds reach $15-20 \mathrm{~m} / \mathrm{s}$. The driving force for the QBO is the vertical transfer of momentum from the troposphere to stratosphere by a broad spectrum of vertically propagating waves including Kelvin and Rossby-Gravity waves (refer Baldwin et al., 2001 for details). There is considerable variability of the QBO in period and amplitude.

The extratropical winter stratosphere is strongly modulated by vertically propagating planetary Rossby waves that are forced by the land sea contrasts and surface topography. The NH has a greater land sea contrast and mountain ranges compared to the $\mathrm{SH}$, thus resulting in an increased amplitude of these waves. These large amplitude waves can disturb the northern polar vortex. Observational analyses have shown that the polar vortex in the NH is highly interannually variable and to some extend, controlled by the phase of the QBO in the tropical stratosphere. Holton and Tan (1980, 1982) were the first who pointed out from observations that the polar vortex tends to be stronger when the QBO is in its westerly phase and tends to be weaker in the easterly QBO phase. For this, Holton and Tan (1980) defined the QBO phase using the equatorial winds at $50 \mathrm{hPa}$ level. Other studies (Wallace et al., 1993; Baldwin and Dunkerton, 1998a) used the first two empirical orthogonal functions of the vertical variations of the equatorial winds, which is similar to

Published by Copernicus Publications on behalf of the European Geosciences Union. 
the $40 \mathrm{hPa}$ equatorial wind for the $\mathrm{NH}$ composites and this analysis is considered to be more robust and even provides a quantitative measure of the Holton-Tan effect.

The effect of the QBO on the NH polar vortex was investigated in several numerical experiments. O'Sullivan and Young (1992) and O'Sullivan and Dunkerton (1994) using a global 3-D mechanistic model forced with a wave-1 perturbation showed the polar vortex being stronger in DecemberJanuary-February months when the tropical winds were westerly. Hamilton (1998) reproduced the Holton-Tan effect making use of a general circulation model run for a continuous 48 -year period with a time varying tropical momentum forcing that produced a 27-month QBO in the equatorial zonal wind with realistic QBO features. Niwano and Takahashi (1998) investigated this feature using their model that spontaneously produces a QBO-like oscillation in the tropics with a period of about 1.4 years and revealed that the $\mathrm{NH}$ polar vortex was weaker in the easterly QBO phase based on the January-March composites of the equatorial wind averaged between 7 and $50 \mathrm{hPa}$. Calvo et al. (2007) using the middle atmosphere version of ECHAM5, which has an internally generated QBO pointed out a significantly warm polar vortex in the easterly QBO phase in January-February months and a cold, strong polar vortex in the westerly QBO phase in the December-January months. Discrepancies were observed in the intensity and the timing when compared with the ERA-40 composites. Stenchikov et al. (2004) used the SKYHI model with a realistic QBO to investigate the effects of the aerosols in the stratosphere on the dynamics of the polar vortex in the context of the volcanic eruption of Mt. Pinatubo. The analysis of the December-January-February averaged $50 \mathrm{hPa}$ geopotential anomalies showed a weakening of the vortex when the QBO is in the easterly phase and an intensification in the westerly QBO phase due to the effects of both QBO and aerosols. Hence, in general, most of the modeling studies show a tendency towards simulating a stronger polar vortex in the westerly QBO phase.

The QBO plays an important role in the distribution of aerosols and chemical constituents like ozone, water vapor and methane in the tropics (Trepte and Hitchman, 1992; Trepte et al., 1993; Baldwin et al., 2001). The QBO's secondary meridional circulation (SMC) which is superimposed upon the Brewer Dobson Circulation consists of an increase of the upwelling in the easterly shear phase and a suppression of the upwelling in the westerly phase (Plumb and Bell, 1982). Divergence of the SMC occurs in the easterly jet, above the easterly shear and below the westerly shear, and convergence occurs in the westerly jet. Hence during the QBO's westerly shear the low-altitude (15-22 km) aerosols and trace gases tend to be spread poleward, while during the QBO's easterly shear, the lower stratospheric trace gases and aerosols remain near the equator (Punge and Giorgetta, 2008; Schoeberl et al., 2008). The QBO also affects the winter stratospheric temperatures depending on the ENSO phase (Garfinkel and Hartmann, 2007; Labitzke, 1987; Labitzke and Van Loon, 1988), for example, our model simulations with observed SSTs and QBO show that when ENSO is in its warm state, the influence of QBO is reduced (Thomas et al., 2009).

Most GCMs are not able to simulate a spontaneous QBO. But, in the recent years, attempts have been made to include QBO forcing in GCMs either by assimilating the observed zonal winds at Singapore to the model winds or by considering a sufficient spatial resolution, a realistic simulation of tropical convection and the consideration of the effects of gravity waves (Hamilton, 1998; Untch, 1998; Bruhwiler and Hamilton, 1999; Scaife et al., 2000; Giorgetta et al., 2002, 2006; Stenchikov et al., 2004).

Here, the sensitivity of the effect of large volcanic eruptions on the high latitude circulation to the QBO phase is evaluated. The main focus is to see whether the responses of temperature and extratropical circulation, as captured by geopotential height changes, to the radiative forcing caused by the Mt. Pinatubo eruption are modulated by the phase of the QBO and ENSO. For this study, the middle atmosphere version of ECHAM5 is modified to include the QBO forcing by nudging the zonal mean zonal winds in the tropics to the prevailing zonal wind observations at Singapore following Giorgetta and Bengtsson (1999). Hence, this paper examines the climate impact of the Mt. Pinatubo eruption if it had erupted during an approximately opposite QBO phase. Mt. Pinatubo erupted on 15 June 1991 during the easterly phase of the QBO at $30 \mathrm{hPa}$ and the change to the westerly phase took place in August 1992 at $30 \mathrm{hPa}$ and remained in the same phase till May 1993. We investigate the impacts in $30 \mathrm{hPa}$ zonal mean temperature and $30 \mathrm{hPa}$ geopotential height.

The response for individual or combined forcings, including volcanic aerosols and ozone anomalies, observed SSTs and the QBO in both the observed and opposite phases are discussed in detail in the following sections.

\section{Model, datasets used and experimental set up}

Both the volcanic aerosol forcing data and the ozone anomaly data were compiled by Stenchikov et al. (2002) from satellite observations after Mt. Pinatubo eruption and are used in this study for the specific model resolution. Further information is described in Thomas et al. (2009).

Simulations are carried out for a 2-year period from June 1991 to May 1993 with the middle atmosphere configuration of ECHAM5 (Special section "Climate models at the Max Planck Institute for Meteorology" in Journal of Climate, 2006, 19, Issue-16, 3769-3987) at T42 horizontal resolution and 39 vertical layers resolving the atmosphere up to $0.01 \mathrm{hPa}$ (Manzini et al., 2006). Both the volcanic aerosol forcing data and the ozone anomaly data were compiled by Stenchikov et al. (2002) and are used in this study for the specific model resolution. 
For the runs including the QBO, a spin up of 17 months is carried out with the observed/opposite QBO phase under climatological SST as boundary conditions. Ten ensemble runs are carried out with different initial conditions. The initial conditions are chosen arbitrarily from the 15 year unperturbed run (excluding the volcanic aerosol forcing and volcanically induced ozone anomalies) under climatological SST as boundary conditions. In order to include the QBO forcing in this study, the zonal winds in the tropics are nudged towards the zonal wind observations at Singapore (Giorgetta and Bengtsson, 1999). The nudging is applied uniformly in a core domain and extends with decreasing nudging rate to the boundary of the domain. The latitudinal core domain specified for the study here is $7 \mathrm{~N}-7 \mathrm{~S}$ and the domain boundary is $10 \mathrm{~N}-10 \mathrm{~S}$. In the vertical, the core domain extends over the levels from $70 \mathrm{hPa}$ to $10 \mathrm{hPa}$. The nudging rate is $(10 \text { days })^{-1}$. This means that the nudging interferes with the dynamics in this well defined domain only on time scales of 10 days and longer.

As mentioned before, there is significant variability of the QBO in period and amplitude. To extract the QBOrelated zonal winds that are opposite of that occurring during the Pinatubo eruption, the correlation co-efficient is calculated between the $50 \mathrm{hPa}$ zonal mean zonal winds at Singapore for the years 1953-2004 and the $50 \mathrm{hPa}$ zonal winds of 1991/1993. The main reason for following this approach instead of changing the sign of the 1991/1993 QBO phases is mainly because the amplitudes and rate of downward propagation of the easterly and westerly phases of the QBO are not identical. The correlation co-efficient is calculated using a sliding window of 24 months of the 1991/1993 period over the observed Singapore winds over the period of 19532004. The time period of maximum negative correlation coefficient is chosen as the opposite QBO phase (hereafter referred to as $\overline{\mathrm{QBO}}$ ) and in this case, the best anti-correlated years (correlation coefficient is -0.86) are from June 1975 May 1977. The zonal winds from observations at Singapore for the period June 1991 - May 1993 and for the period June 1975 - May 1977 are presented in Fig. 1. The easterly winds are denoted by negative values (blue shades) and westerly winds, by positive values (yellow shades). It can be seen that the amplitudes of the westerly and easterly winds are comparable in both cases. The phase change at $30 \mathrm{hPa}$ takes place in month 14 after June 1991 (around August 1992) and in $\overline{\mathrm{QBO}}$, this phase change occurs in month 11 after June 1975 (around mid May 1976). The zonal mean zonal winds of opposite sign for the period 1991/1993 are well represented by the period 1975/1977. Since each of the QBO cycle is unique, this is the best correlation possible within the available record.

Simulations with the prescribed volcanic aerosols and volcanically induced ozone anomalies (hereafter, referred to as perturbed runs) are carried out with observed SST and with the observed/opposite QBO phases as boundary conditions. The individual QBO responses are labelled by QBO
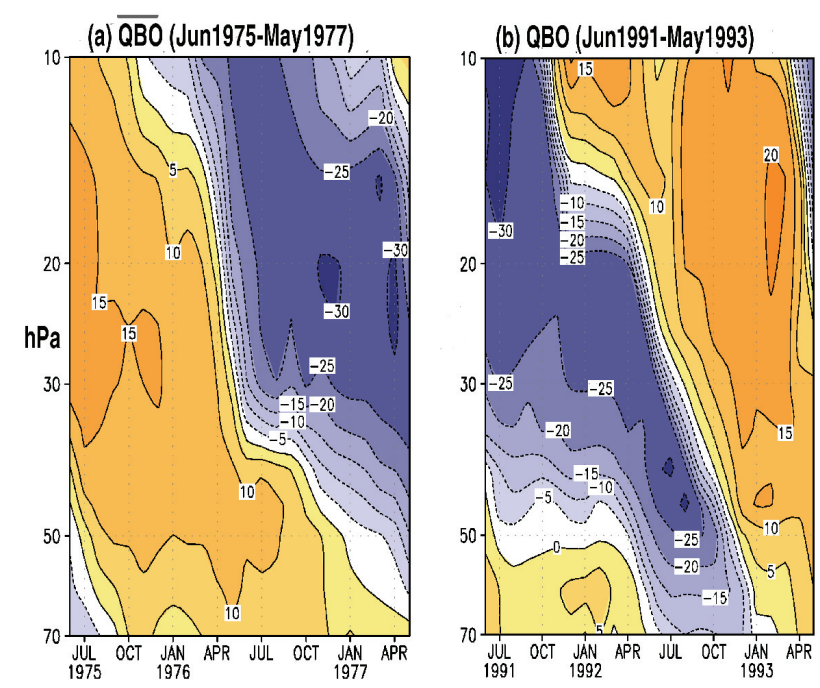

Fig. 1. Monthly averaged observed zonal mean zonal wind $(\mathrm{m} / \mathrm{s})$ at Singapore for (a) June 1975 - May 1977 and (b) June 1991 May 1993. Negative values are shaded in colors of blue and are easterlies and the positive values are shaded in colors of yellow and are the westerlies. The contour interval is $5 \mathrm{~m} / \mathrm{s}$.

when the observed QBO phase is prescribed and by $\overline{\mathrm{QBO}}$ when the opposite QBO phase is prescribed. These responses are calculated as a difference of the unperturbed QBO run ( $\overline{\mathrm{QBO}}$ run) with climatological SST as boundary conditions, denoted by $\mathrm{Q}_{u}\left(\overline{\mathrm{Q}}_{u}\right)$ from the control climatological run, $\mathrm{C}_{u}$ (unperturbed run). The responses to the combined aerosol + ocean + QBO forcing are denoted by AOQ for the observed QBO phase and by $\mathrm{AO} \overline{\mathrm{Q}}$ for the opposite QBO phase. These responses are calculated as the difference between the combined $\mathrm{AOQ} / \mathrm{AOQ}$ experiment and the unperturbed run with climatological $\mathrm{SST}\left(\mathrm{C}_{u}\right)$ as boundary conditions.

Two 20 year model simulations with climatological SST as boundary conditions, including and excluding a QBO are referenced in this paper from the study by Punge and Giorgetta (2008). These simulations were carried out with the chemistry climate model, MAECHAM4-CHEM. The MAECHAM4-CHEM consists of the middle atmosphere version of the ECHAM4 climate model (Manzini and McFarlane, 1998; Roeckner et al., 1996) and the interactively coupled chemistry model, CHEM (Steil et al., 1998; Manzini et al., 2003).

\section{Results and discussion}

The first part of this section discusses the responses in temperature and geopotential height at $30 \mathrm{hPa}$ to the QBO phases alone. The second part discusses the dynamical responses to the combined forcing by volcanic aerosols, El Niño and different QBO phases. 

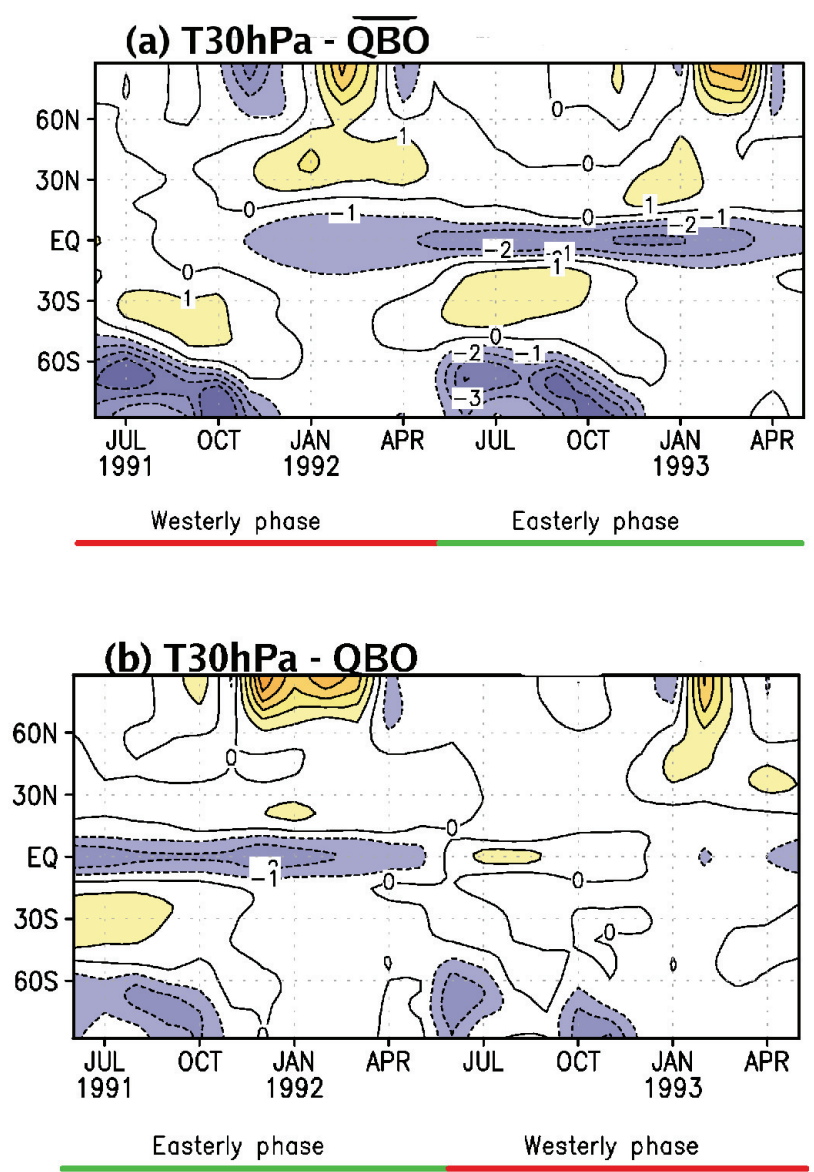

(c) QBO net effect in T30hPa

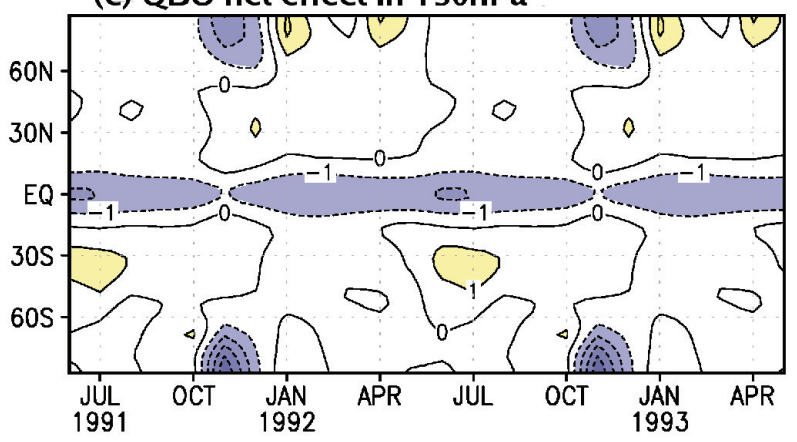

Fig. 2. Zonally averaged lower stratospheric temperature anomalies (K) at $30 \mathrm{hPa}$ for two years following the eruption when (a) QBO is in the opposite shear (b) QBO is in the observed shear and (c) the climatolgical mean of the net QBO effect in zonal mean $30 \mathrm{hPa}$ temperature (Punge and Giorgetta, 2008). The latitudinal extent is shown in the y-axis and is from $90 \mathrm{~S}-90 \mathrm{~N}$. The anomalies in (a) and (b) are significant at $>95 \%$ confidence level between $30 \mathrm{~N}$ and $30 \mathrm{~S}$ (not shown) and the winter anomaly north of $60 \mathrm{~N}$ of OctoberNovember-December1991 in (a) is also significant at $>90 \%$ confidence level.

\subsection{Response of temperature and geopotential height at $30 \mathrm{hPa}$ to pure QBO forcing}

\subsubsection{Lower stratospheric temperature response at $30 \mathrm{hPa}$}

The pure stratospheric temperature response to the two QBO phases at $30 \mathrm{hPa}$, namely one for the phase change from easterly to westerly (QBO) and the other from westerly to easterly $(\overline{\mathrm{QBO}})$ is investigated. Figure 2 shows the lower stratospheric temperature response to (a) $\overline{\mathrm{QBO}}$ and to (b) the observed QBO phase. The anomalies are significant at $>95 \%$ level between $30 \mathrm{~N}$ and $30 \mathrm{~S}$ (not shown). A cooling of about $1-2 \mathrm{~K}$ is simulated in the latitudinal belt from $10 \mathrm{~N}-10 \mathrm{~S}$ from June 1991 - April 1992 in Fig. 2b and from January 1992 - May 1993 in Fig. 2a during the easterly QBO shear and positive anomalies are evident in the mid latitudes. Whereas positive temperature anomalies are evident along the equator and negative anomalies over the subtropics during the westerly shear of QBO. The opposite temperature signals in the subtropics are the result of the compensating branches of the secondary circulation of the QBO. This feature is consistent with previous studies by Baldwin et al. (2001). However, the temperature response associated with the westerly phase of the QBO in Fig. 2a, b is comparatively weaker. This asymmetry between strong cold and weak positive equatorial temperature anomalies at $30 \mathrm{hPa}$ results from the bias in climatological temperature of the reference simulation $\mathrm{C}_{u}$, which does not include the QBO and therefore misses the long term net effects of the QBO (Punge and Giorgetta, 2008). The climatological mean differences in the annual cycle of lower stratospheric temperature at $30 \mathrm{hPa}$ between two 20 year model simulations including and excluding the QBO are shown in Fig. 2c. It can be clearly seen that the stratospheric temperature climatology at $30 \mathrm{hPa}$ in the tropics is colder by up to $-1.5 \mathrm{~K}$ in the model including the QBO than in the model excluding the QBO (Punge and Giorgetta, 2008). This explains why the positive temperature anomalies with respect to the control simulation, $\mathrm{C}_{u}$ excluding the QBO, as shown in Fig. 2a and b, are weaker than the observed positive temperature anomalies with respect to the observed climatology, which includes the QBO.

Below normal temperature anomalies are noticeable in the pure QBO response during the westerly phase of the QBO in Northern Hemisphere $(\mathrm{NH})$ winter during the months of October-November-December in the polar latitudes as in Fig. 2a and during November-December as in Fig. 2b. However, the anomalies are statistically significant at $90 \%$ level (not shown) in pure $\overline{\mathrm{QBO}}$ and are weak and insignificant in the pure QBO experiment. This cooling may be associated with the strengthening of the polar vortex. Though a warm and weak polar vortex corresponding to the positive temperature anomalies is seen during the easterly QBO phases, the anomalies are not significant. 
(a) $\overline{\text { QBO }-~ D J F ~} 1991 / 92$

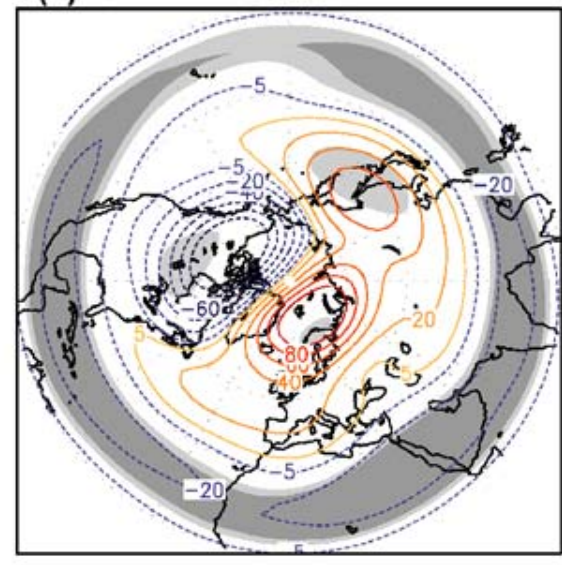

(c) QBO - DJF 1991/92

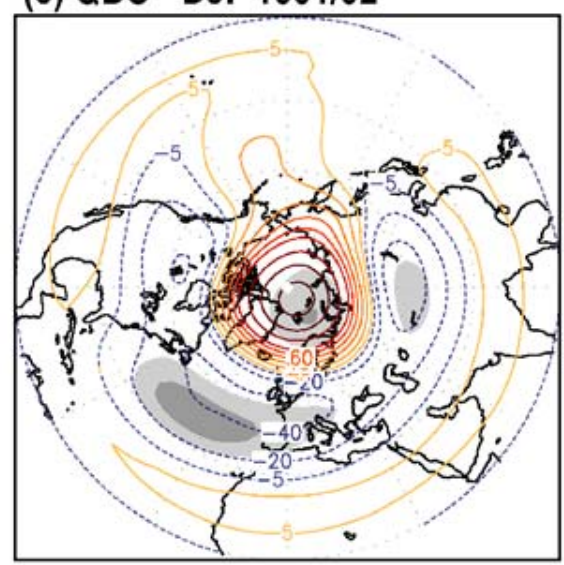

(b) $\overline{Q B O}$ - DJF $1992 / 93$

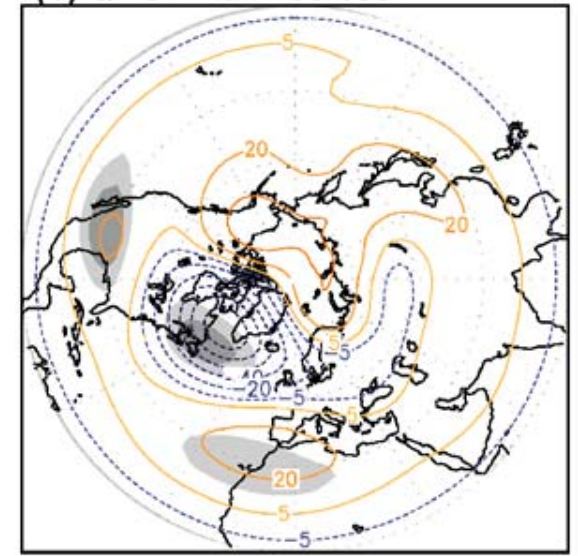

(d) QBO - DJF 1992/93

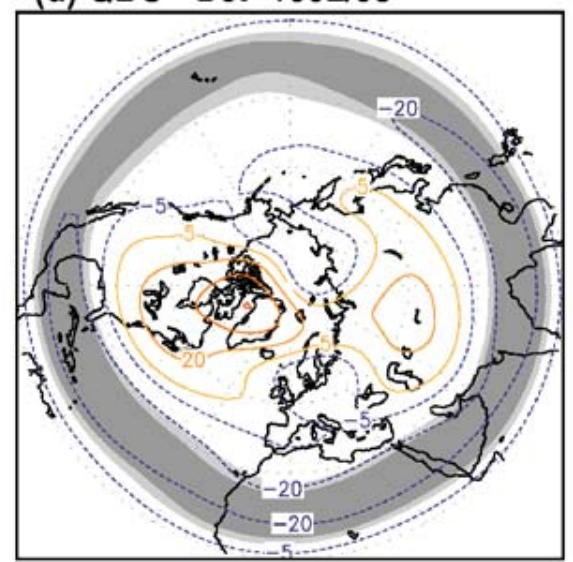

Fig. 3. Geopotential height anomalies (m) at $30 \mathrm{hPa}$ for (a) QBO: DJF 1991/1992 (b) QBO: DJF 1992/1993, when the opposite QBO phase is prescribed; and for (c) QBO: DJF 1991/1992 and (d) QBO: DJF 1992/1993, when the observed QBO phase is prescribed. The shading denotes two levels $(95 \%$ and $90 \%)$ of statistical significance in the order of lighter shading. Contours are at $20 \mathrm{~m}$ intervals until $100 \mathrm{~m}$ and then the intervals are at $40 \mathrm{~m}$. A $5 \mathrm{~m}$ contour is added in the figures. The projection spans from $10 \mathrm{~N}$ to $90 \mathrm{~N}$ latitudinally.

\subsection{2 $30 \mathrm{hPa}$ geopotential height response in boreal winter}

Studies by Holton and Tan $(1980,1982)$ show that significantly lower geopotential heights are evident in the northern high latitudes in winter during the westerly QBO phase than during the easterly phase. The anomalies in the $30 \mathrm{hPa}$ geopotential height in response to the $\overline{\mathrm{QBO}}$ phase are presented in Fig. 3a, b for the two boreal winters of 1991/1992 and 1992/1993. In Fig. 3a, the QBO is in its westerly phase at $30 \mathrm{hPa}$ and in Fig. 3b, the QBO is in its easterly phase. It is evident that irrespective of the QBO phase, the model simulates negative geopotential height anomalies (up to $-100 \mathrm{~m}$ ) over northern North America and parts of Greenland in the first winter and over parts of northern North America, Greenland and northern Atlantic in the second winter. However, in these cases it is difficult to decide whether the vortex is stronger or not. Above normal geopotential heights (up to $100 \mathrm{~m}$ ) are evident over northern Eurasia in the first winter and comparatively weaker positive anomalies over Siberia in the second winter when the opposite QBO phase is prescribed.

For comparison, the anomalies with the observed QBO phase are shown in Fig. 3c, d. Here, the QBO is in its easterly phase in the winter of 1991/1992 and in westerly phase in 1992/1993. The model simulates an anomalously statistically significant weak vortex (up to $220 \mathrm{~m}$ ) during the easterly QBO phase in consistent with previous studies, but the anomalies are much weaker and insignificant during the westerly QBO phase.

As mentioned in the introduction, previous studies have shown that the vortex is strong and cold during the westerly QBO phase and warm and weak during the easterly QBO phase. The model simulates an anomalously warm vortex as 
(a) $A O \bar{Q}$

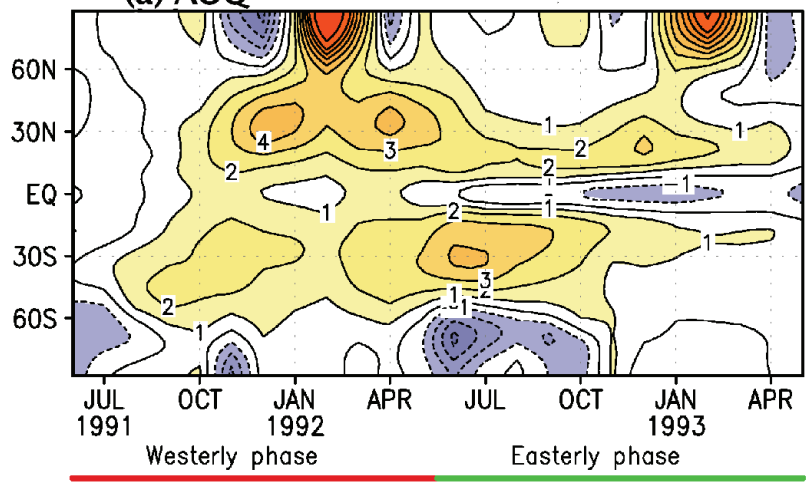

(b) AOQ

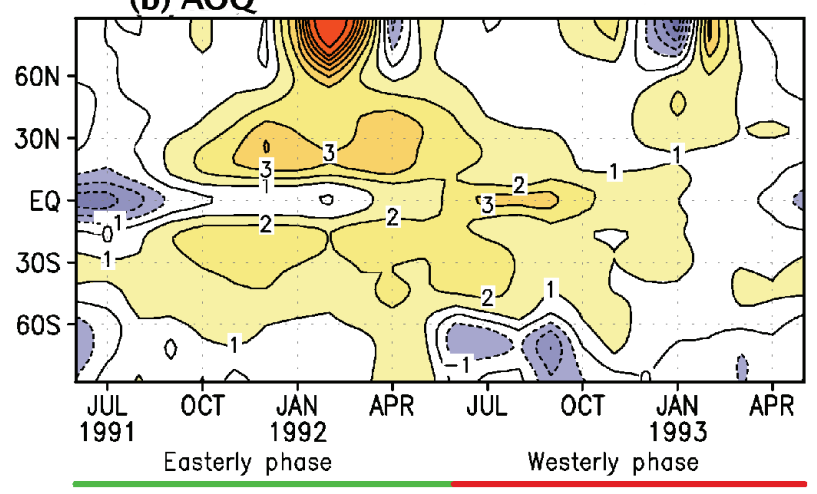

Fig. 4. Zonally averaged lower stratospheric temperature anomalies (K) at $30 \mathrm{hPa}$ for two years following Mt. Pinatubo eruption for (a) AOQ with the opposite QBO phase and (b) AOQ experiment with observed QBO phase. The QBO phases encountered during (a) and (b) are shown by the colored lines. The anomalies within the $1 \mathrm{~K}$ contour interval in the latitudinal band of $60 \mathrm{~N}$ and $60 \mathrm{~S}$ is statistically significant at $>95 \%$ confidence level (not shown). The winter anomalies north of $60 \mathrm{~N}$ are also significant at $>90 \%$ confidence level for NDJFM of 1991/1992 and DJFM of 1992/1993 in (a) and for JFM of 1992 in (b).

in Fig. 3c, whereas this is not the case in Fig. 3b, even though the QBO is in its easterly phase. This may be due to the averaging kernels used here. This can be explained by analyzing the temperature anomalies shown in Fig. 2a, b. It can be seen that during the second winter in Fig. 2a, positive temperature anomalies are simulated in January-February-March, rather than December-January-February, thereby showing a weaker picture of the warm vortex in the geopotential height anomalies. Similarly, the strengthening of the polar vortex during the westerly QBO phase is not simulated during the first winter in Fig. 3a. Here, too, the cold temperature anomalies (Fig. 2a) during the first winter occurs during the October-November-December months, rather than December-January-February months. Also, it has to be noted that here we try to simulate one event rather than calculate the composites of several cases as is carried out in the previous modeling/observational studies (Holton and Tan, 1980; Niwano and Takahashi, 1998; Calvo et al., 2007). Hence, the vortex is highly sensitive to the winter months selected and the dynamics of the vortex is non-linear.

\subsection{Differences in the climate response to volcanic aerosol forcing in $\mathrm{QBO}$ and $\overline{\mathrm{QBO}}$ phases}

\subsubsection{Lower stratospheric temperature response}

Figure 4 shows the $30 \mathrm{hPa}$ temperature response when the aerosol forcing, El Niño and QBO effects are included for two years following the eruption. The difference between Fig. 4a and $\mathrm{b}$ is that the former has the opposite QBO phase and the latter has the observed phase as shown by the color bars given at the bottom of the figure. Here, the anomalies within the $1 \mathrm{~K}$ contour interval in the latitudinal band of $60 \mathrm{~N}$ and $60 \mathrm{~S}$ is statistically significant at $>95 \%$ confidence level (not shown). The effects due to the contrasting QBO phases are clearly evident. A cooling of about $1-2 \mathrm{~K}$ is only visible after June 1992 in (a), and only until October 1991 in (b) in the latitudinal belt $10 \mathrm{~N}-10 \mathrm{~S}$, and warmer temperatures are seen in the subtropics. This dual peak with a relative maximum in the subtropics and minimum at the equator during the easterly phase of the QBO is well simulated by both experiments. Strong positive anomalies are simulated around $30 \mathrm{~N}$ in both the experiments in January-February-March'92 and this may be due to enhancement of vertical wave propagation during El Niño events as shown in the part-1 of this paper (Thomas et al., 2009).

As mentioned in Sect. 3.1.1, below normal temperature anomalies are exhibited in the pure QBO response during the westerly phase of the QBO in Northern Hemisphere $(\mathrm{NH})$ winter during the months of October-NovemberDecember in the polar latitudes in Fig. 2a and during November-December as in Fig. 2b. This cooling is more prominent during the westerly phases in AOQ where statistically significant (significant at 90\% level) cooling is persistent over October-November-December, whereas the cooling is not significant and is confined to November-December in AOQ. Significant above normal temperatures occurs north of $60 \mathrm{~N}$ during the easterly phases of QBO in December-January-February-March months (December-January-February-March'1991/1992 in Fig. 4b and December-January-February-March'1992/1993 in Fig. 4a) and may be associated with a warm and weak polar vortex. These anomalies are statistically significant at 90\% significance level (not shown). Hence, when one compares these results with the pure QBO temperature responses, it can be seen that the strong anomalies in the high latitudes are amplified by the complex forcing by aerosols, QBO and SSTs. 
(a) $A O \bar{Q}$ - DJF $1991 / 92$

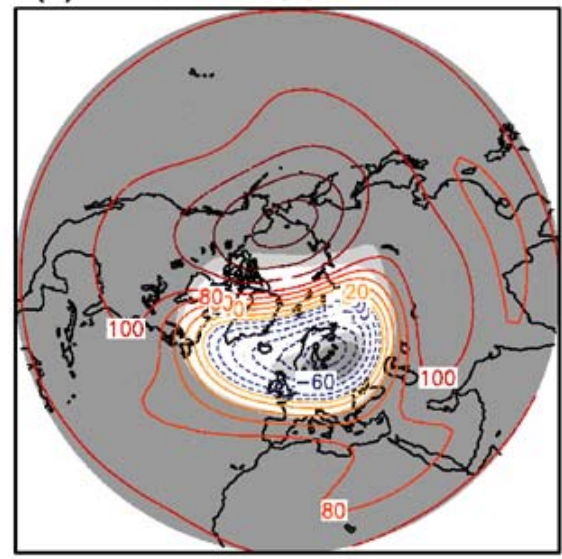

(c) AOQ - DJF 1991/92

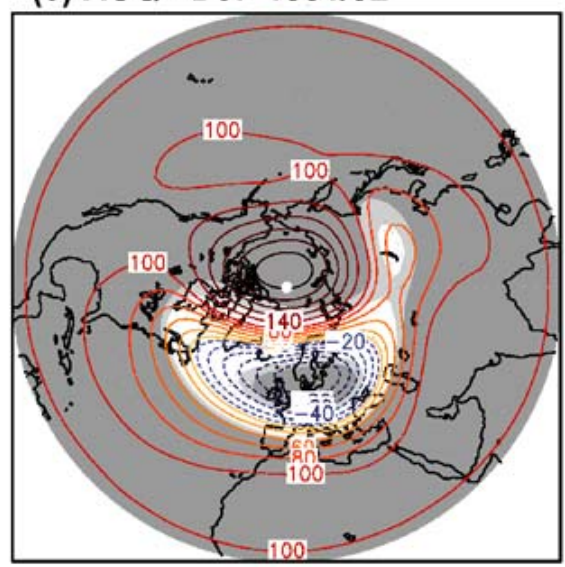

(b) $A O \bar{Q}$ - DJF $1992 / 93$

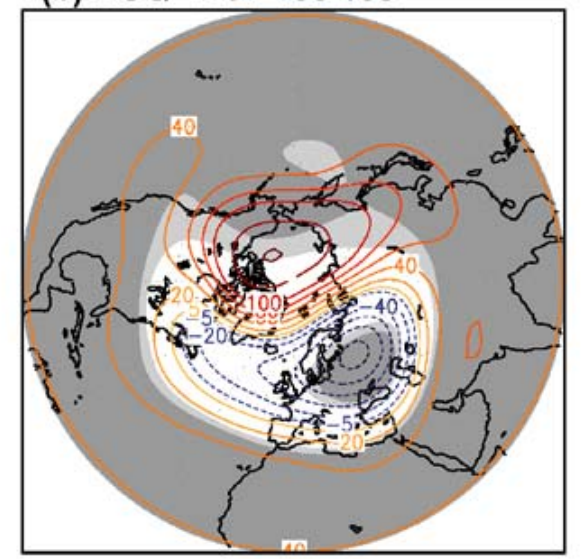

(d) AOQ - DJF 1992/93

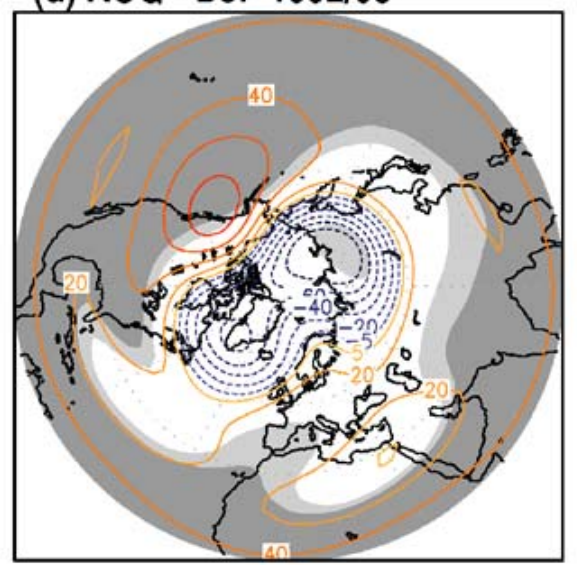

Fig. 5. Geopotential height anomalies (m) for (a) AOQ: DJF 1991/1992 (b) AOQ: DJF 1992/1993, when the opposite QBO phase is prescribed and for (c) AOQ: DJF 1991/1992 and (d) AOQ: DJF 1992/1993, when the observed QBO phase is prescribed. The shading denotes two levels (95\% and 90\%) of statistical significance in the order of lighter shading. Contours are at $20 \mathrm{~m}$ intervals up to $100 \mathrm{~m}$ and then the intervals are at $40 \mathrm{~m}$. The projection spans from $10 \mathrm{~N}$ to $90 \mathrm{~N}$ latitudinally.

\subsection{2 $30 \mathrm{hPa}$ geopotential height response}

The geopotential height anomalies at $30 \mathrm{hPa}$ for the two winters following the eruption are shown in Fig. 5a, b in AOQ and in Fig. 5c, d in AOQ runs. The anomalies in AOQ during the winters of 1991/1992 and 1992/1993 exhibit a wave number one pattern with positive anomalies over northern Pacific, Canada, Alaska and Siberia and negative anomalies over north western Europe and North Atlantic. The geopotential height anomalies reach as low as $-100 \mathrm{~m}$ and as high as $180-220 \mathrm{~m}$. There are no notable differences between the anomalies of the two winters in the AOQ $\overline{\mathrm{Q}}$ experiments except that the anomalies in the second winter following the eruption are relatively larger than in the first winter. As mentioned before, the westerly phase of the QBO favors a strong polar vortex. But, in $\mathrm{AO} \overline{\mathrm{Q}}$, the westerly phase occurs during the El Niño winter, which in turn, disturbs the polar vortex due to the increased vertical propagation of waves. However, a closer look into the corresponding temperature anomalies north of $60 \mathrm{~N}$ in Fig. 4a, b shows statistically significant negative temperature anomalies in November-December 1991 during the westerly QBO phase which can be related to a strong and cold polar vortex, and a disturbed vortex thereafter in January-February. Hence, the negative anomaly in Fig. 5a which is averaged over the negative and positive anomalies occurring in December-January-February, is not significant.

The responses to the combined forcings that includes the observed QBO phase are shown in Fig. 5c, d. The anomaly pattern in Fig. 5c is similar to Fig. 5a, irrespective of the QBO phases. This can be also seen in the corresponding temperature anomalies during the first winters (Fig. 4a, b) that indicates strong positive temperature anomalies during the January-February-March months that can be related to 
a weak, warm polar vortex irrespective of the QBO phases. This may be due to the fact that the effects of the 1991/1992 El Niño override the influence of the QBO. However, the model simulates a strong polar vortex in the second winter with a large center of low geopotential height anomalies over the Arctic polar cap, Greenland and north eastern Europe and Siberia in AOQ when the QBO is in the westerly phase. Hence, in general, our analysis supports the studies by Holton and Tan $(1980,1982)$.

\section{Conclusions}

The sensitivity of the climate impact of the Mt. Pinatubo eruption to the different QBO phases is investigated. Mt. Pinatubo erupted during the easterly phase of the QBO and the phase change took place 14 months after the eruption. Here, two cases are considered: firstly, the observed QBO of June 1991 to May 1993 when the Mt. Pinatubo eruption influenced the climate, and secondly, the QBO of June 1975 to May 1977, which is highly anti-correlated to the first one and hence, represents here the QBO in opposite phase. Additionally, the pure QBO experiments are also evaluated to see whether the model can simulate the tropical and extratropical responses as well. Our results can be summarized as follows:

(1) The individual QBO (when observed QBO phase is included) and $\overline{\mathrm{QBO}}$ responses in the lower stratospheric temperature at $30 \mathrm{hPa}$ show a dual peak with cooling along the equator and warming over the subtropics associated with the easterly phase of the QBO and the opposite is shown during the westerly QBO phase. This is in agreement with previous studies. The similar tropical signature is also evident in the combined responses.

(2) The responses of QBO show negative geopotential height anomalies centered over northern North America and Greenland in both winters, irrespective of the QBO phase change. The strengthening of the polar vortex during the westerly QBO phase is not evident in the first winter in this case. This may be due to months selected for averaging. Study by Calvo et al. (2007) show a strengthening of the polar vortex in the westerly QBO phases in the December-January composites. The temperature anomalies in the pure $\overline{\mathrm{QBO}}$ response show colder anomalies during October-November-December months and not during the December-January-February months considered for averaging. The model simulates a warm and weak polar vortex in the first winter and the vortex is disturbed in the second winter when the observed QBO phase is prescribed.

(3) Below normal temperature anomalies are exhibited north of $60 \mathrm{~N}$ during the westerly QBO phases in October-November-December' 1991 months in AOQ and in November-December' 1992 in AOQ̄. This may be associated with the strengthening of the polar vortex in agreement with previous studies. These anomalies are also obvious in the westerly phases in the pure QBO responses, except that the anomalies in the pure responses are weaker.
(4) The simulated vortex is weak and shifted over northern Europe in the combined AOQ response irrespective of the QBO phases in the first winters (December-JanuaryFebruary averaged). Similar response is also evident in the temperature anomalies north of $60 \mathrm{~N}$ during the months of January-February-March'1992. This may be because of the increased vertical wave activity during El Niño winters making the vortex much weaker. However, the model simulates a strong polar vortex during the second winter when the QBO is in its westerly phase in the AOQ experiment and El Niño is no longer active.

Our results show that the climate response after explosive tropical eruptions is significantly modulated by the QBO phase. Major differences owing to the QBO phase are apparent in the tropics and extratropics in the lower stratosphere temperature response. This study also shows that the model has a tendency to simulate a strong polar vortex during the westerly QBO phase and vice versa. The use of prescribed aerosol and nudged QBO in this study restricts the understanding of the effects of the different QBO phases on the transport and mixing of the aerosols. However, studies will be carried out to investigate the effect of aerosols on the QBO.

Acknowledgements. Computations were done at the German Climate Computer Center (DKRZ). C. T. is supported by the German Science Foundation DFG grant TI 344/1-1. G. S. was supported by NSF grant ATM-0351280 and NASA grant NNG05GB06G. We would also like to acknowledge ERA-40 project for the data used in this study obtained from the ECMWF data server.

The service charges for this open access publication have been covered by the Max Planck Society.

Edited by: P. Haynes

\section{References}

Andrews, D. J., Holton, J. R., and Leovy, C. B.: Middle atmosphere dynamics, Academic Press, 489 pp., 1987.

Baldwin, M. P. and Dunkerton, T. J.: Biennial, quasi-biennial and decadal oscillations of potential vorticity in the northern stratosphere, J. Geophys. Res., 103, 3919-3928, 1998a.

Baldwin, M. P., Gray, L. J., Dunkerton, T. J., Hamilton, K., Haynes, P. H., Randel, W. J., Holton, J. R., Alexander, M. J., Hiorta, I., Horinouchi, T., Jones, D. B. A., Kinnersley, J. S., Marquardt, C., Sato, K., and Takahashi, M.: The quasi-biennial oscillation, Rev. Geophys., 39(2), 170-229, 2001.

Bruhwiler, L. and Hamilton, K.: A numerical simulation of the stratospheric ozone quasi biennial oscillation using a comprehensive general circulation model, J. Geophys. Res., 104, 30523$30557,1999$.

Calvo, N., Giorgetta, M. A., and Pena-Ortiz, C.: Sensitivity of the boreal winter circulation in the middle atmosphere to the quasibiennial oscillation in MAECHAM5 simulations, J. Geophys. Res., 112, D10124, 2007. 
Garfinkel, C. I. and Hartmann, D. L.: Effects of El Niño -Southern Oscillation and the Quasi-Biennial Oscillation on polar temperatures in the stratosphere, J. Geophys. Res., 112, D19112, doi:10.1029/2007JD008481, 2007.

Giorgetta, M. and Bengtsson, L.: The potential role of the quasibiennial oscillation in the stratosphere-troposphere exchange as found in water vapor in general circulation model experiments, J. Geophys. Res., 104, 6003-6019, 1999.

Giorgetta, M., Manzini, E., and Roeckner, E.: Forcing of the quasibiennial oscillation from a broad spectrum of atmospheric waves, Geophys. Res. Lett., 29, 86-90, 2002.

Giorgetta, M., Manzini, E., Roeckner, E., Esch, M., and Bengtsson, L.: Climatology and forcing of the Quasi-Biennial Oscillation in the MAECHAM5 model, J. Climate, 19, 3882-3901, 2006.

Graf, H.-F., Kirchner, I., Robock, A., and Schultz, I.: Pinatubo eruption winter climate effects: Model versus observations, Clim. Dynam., 9, 81-93, 1993.

Hamilton, K.: Effects of an imposed quasi-biennial oscillation in a comprehensive troposphere-stratosphere-mesosphere general circulation model, J. Atmos. Sci., 55, 2393-2418, 1998.

Holton, J. R. and Tan, H.-C.: The influence of the equatorial quasibiennial oscillation on the global circulation at $50 \mathrm{mb}$, J. Atmos. Sci., 37, 2200-2208, 1980.

Holton, J. R. and Tan, H.-C. : The quasi biennial oscillation in the Northern Hemisphere lower stratosphere, J. Meteorol. Soc. Jpn., 60, 140-148, 1982.

Kirchner, I. and Graf, H.-F.: Volcanoes and El Niño: Signal separation in Northern Hemisphere winter, Clim. Dynam., 11, 341358,1995 .

Labitzke, K. and Van Loon, H.: Association between the 11-year solar cycle, the QBO, and the atmosphere, Part I, The troposphere and the stratosphere in the Northern Hemisphere in winter, J. Atmos. Terr. Phys., 50, 197-207, 1988.

Labitzke, K.: Sunspots, the QBO and the stratospheric temperature in the North Polar region, Geophys. Res. Lett., 14, 535-537, 1987.

Manzini, E. and McFarlane, N. A.: The effect of varying the source spectrum of a gravity wave parameterization in a middle atmosphere general circulation model, J. Geophys. Res., 103, 31523 31539, 1998.

Manzini, E., Steil, B., Brühl, C., Giorgetta, M. A., and Kruger, K.: A new interactive chemistry-climate model: Sensitivity of the middle atmosphere to ozone depletion and increase in greenhouse gases and implications for recent stratospheric cooling, J. Geophys. Res., 108, 4429, doi:10.1029/2002JD002977, 2003.

Manzini, E., Giorgetta, M. A., Esch, M., Kornblueh, L., and Roeckner, E.: The influence of sea surface temperatures on the northern winter stratosphere: Ensemble simulations with the MAECHAM5 model, J. Climate, 19, 3863-3881, 2006.

Niwano, M. and Takahashi, M.: The influence of the equatorial QBO on the Northern Hemisphere winter circulation of a GCM, J. Meteorol. Soc. Jpn., 76, 453-461, 1998.

O'Sullivan, D. and Dunkerton, T. J.: Seasonal development of the extratropical QBO in a numerical model of the middle atmosphere, J. Atmos. Sci., 51, 3706-3721, 1994.

O'Sullivan, D. and Young, R. E.: Modeling the quasi-biennial oscillation's effect on the winter stratospheric circulation, J. Atmos. Sci., 49, 2437-2448, 1992.
Plumb, R. A. and Bell, R. C.: A model of the quasi-biennial oscillation on an equatorial beta-plane, Q. J. Roy. Meteor. Soc., 108, 335-352, 1982.

Punge, H. J. and Giorgetta, M. A.: Net effect of the QBO in a chemistry climate model, Atmos. Chem. Phys., 8, 6505-6525, 2008, http://www.atmos-chem-phys.net/8/6505/2008/.

Roeckner, E., Arpe, K., Bengtsson, L., Christoph, M., Claussen, M., Dumenil, L., Esch, M., Giorgetta, M. A., Schlese, U., and Schulzweida, U.: The atmospheric general circulation model ECHAM4: Model description and simulation of present-day climate, Max Planck Institut for Meteorology, Report No., 218, Hamburg, 1996.

Robock, A. and Mao, J.: The volcanic signal in surface temperature observations, J. Climate, 8, 1086-1103, 1995.

Scaife, A., Buchart, N., Warner, C. D., Stainforth, D., Norton, W., and Austin, J.: Realistic quasi-biennial oscillation in a simulation of the global climate, Geophys. Res. Lett., 27, 3481-3484, 2000.

Schoeberl, M. R., Douglass, A. R., Newman, P. A., Lait, L. R., Lary, D., Waters, J., Livesey, N., Froidevaux, L., Lambert, A., Read, W., Filipiak, M. J., and Pumphrey, H. C.: QBO and annual cycle variations in tropical lower stratosphere trace gases from HALOE and Aura MLS Observations, J. Geophys. Res., 113, D05301, doi:10.1029/2007JD008678, 2008.

Steil, B., Dameris, M., Brühl, C., Crutzen, P. J., Grewe, V., Ponater, M., and Sausen, R.: Development of a chemistry module for GCMs: first results of a multiannual integration, Ann. Geophys., 16, 205-228, 1998, http://www.ann-geophys.net/16/205/1998/.

Stenchikov, G., Robock, A., Ramaswamy, V., Schwarzkopf, M. D., Hamilton, K., and Ramachandran, S.: Arctic Oscillation response to the 1991 Mount Pinatubo eruption: Effects of volcanic aerosols and ozone depletion, J. Geophys. Res., 107, 1-16, 2002.

Stenchikov, G., Hamilton, K., Robock, A., Ramaswamy, V., and Schwarzkopf, M. D.: Arctic Oscillation response to the 1991 Pinatubo eruption in the SKYHI general circulation model with a realistic quasi-biennial oscillation, J. Geophys. Res., 109, 2004.

Thomas, M. A., Timmreck, C., Giorgetta, M. A., Graf, H.-F., and Stenchikov, G.: Simulation of the climate impact of Mt. Pinatubo eruption using ECHAM5 - Part 1: Sensitivity to the modes of atmospheric circulation and boundary conditions, Atmos. Chem. Phys., 9, 757-769, 2009, http://www.atmos-chem-phys.net/9/757/2009/.

Trepte, C. R. and Hitchman, M. H.: Tropical stratospheric circulation deduced from satellite aerosol data, Nature, 355, 626-628, 1992.

Trepte, C. R., Veiga, R. E., and McCormick, M. P.: The poleward dispersal of Mount Pinatubo volcanic aerosol, J. Geophys. Res., 98, 18563-18573, 1993.

Untch, A.: A simulation of the quasi-biennial oscilaltion with the ECMWF model, Research Activities in Atmospheric and Ocean Modelling, WMO, 626-627, 1998.

Wallace, J. M., Panetta, R. L., and Estberg, J.: Representation of the equatorial stratospheric quasi-biennial oscillation in EOF phase space, J. Atmos. Sci., 50, 1751-1762, 1993.

Yasunari, T.: A possible link of the QBOs between the stratosphere, troposphere and sea surface temperature in the tropics, J. Meteorol. Soc. Jpn., 67, 483-493, 1989. 